\title{
A MULTI-OBJECTIVE DECISION-SUPPORT MODEL FOR SELECTING ENVIRONMENTALLY CONSCIOUS HIGHWAY CONSTRUCTION METHODS
}

\author{
Gulbin OZCAN-DENIZ ${ }^{\mathrm{a}}$, Yimin ZHU \\ ${ }^{a}$ Civil and Architectural Engineering and Construction Management, Milwaukee School of Engineering, \\ Milwaukee, 53202 WI, USA \\ ${ }^{b}$ Department of Construction Management, Louisiana State University, Baton Rouge, 70803 LA, USA
}

Received 03 Nov 2012; accepted 11 Jan 2013

\begin{abstract}
The construction industry has a considerable share in overall resource and energy consumption. Consequently, decision-makers try to achieve environmentally conscious construction by integrating environmental objectives into the selection of construction elements. Due to the complexity of construction projects, it is a known challenge to provide an effective mechanism to select the most feasible construction methods. Thus, it is crucial to learn the interdependency between various resource alternatives, such as material and equipment type, under various project conditions like unavailability of resources. An analytic network process (ANP) was used in this study to construct a decision model for selecting the most feasible construction method. Data collected via interviews with highway construction experts were used to model the dependency between decision parameters, such as project conditions and resource performance indicators. The proposed ANP model output the relative importance weights of decision parameters so that they can be used to identify environmentally conscious construction methods. The proposed mechanism is a valuable asset for construction decision-makers especially when their ability to select construction methods is limited by project constraints. Although the model was tested in a highway project in this paper, it can be further extended to benefit building construction and sustainable decision-making problems.
\end{abstract}

Keywords: sustainable construction, analytic network process, highway construction, construction methods, multi-criteria decision-making.

\section{Introduction}

The environmental impact of construction sector is accounted for $30-40 \%$ of natural resource consumption in industrialized countries (Pulselli et al. 2009). Due to the significant amount of energy consumption, the building industry had several environmental concerns, such as harmful emissions. The construction industry was responsible for $30 \%$ of global annual green house gas (GHG) emissions, and consumes up to $40 \%$ of all energy (UNEP-SBCI 2009). In the United States, the construction sector accounted for $39 \%$ of primary energy use and $38 \%$ of $\mathrm{CO} 2$ emissions (USGBC 2008). Considering the large number of annual construction projects worldwide, as well as their share in the overall resource consumption, overlooking the environmental impact of construction processes can have seriously adverse effects on the natural environment.

Environmentally conscious construction is defined as the encouragement of ecological, economic, and social-cultural sustainability in buildings (Kua, Lee 2002); the concept therefore includes environmental considerations, as well as other objectives. Selih (2007) suggested environmental impact in addition to traditional performance measures, such as cost, for the evaluation of projects.

The selection of construction methods, including material types and operation methods, has significant impact on the performance of a project. Many researchers have looked into project performance related to environmental impact and focused on reducing environment impact by using environmentally-friendly construction methods. For example, Hendrickson and Horvath (2000) demonstrated the importance of understanding the environmental impact of construction operations. Gangolells et al. (2009) studied the impact and severity of environmental performance related to construction. Although the connection between environmental impact and construction methods is not a new subject, many questions remain unanswered due to the complexity of construction projects.

The selection of construction methods is typically influenced by various changing factors, which are based on the different interests of involved parties (Cole 1998). Interests, such as profit and time, have received more attention

Corresponding author: Gulbin Ozcan-Deniz

E-mail:ozcan@msoe.edu 
than the intricate impact of building processes, materials, and technologies on the natural environment. Such preference is clearly reflected in existing literature in construction engineering and management. On the other hand, it is commonly noted that successful sustainable construction depends on meaningful integration of multiple project performance criteria, including environmental impact.

With a potentially large set of alternatives in material types, operation methods, and external project conditions affecting the availability and/or performance of resources, construction professionals often find themselves dealing with complex (sometimes conflicting) performance criteria, and in need of a mechanism to determine the most desirable construction method to successfully satisfy different project conditions and objectives. The challenge in searching for the most feasible construction method is that a decision-maker normally does not know the interdependencies among resources or external factors at the time of decision-making.

External project conditions can be as important as the performance characteristics of resources in construction method selection. There are several studies that discussed decision-making and construction operations simultaneously. For example, Zayed and Halpin (2000) studied the necessity of decision-making as a part of construction operations and created time-cost quantity charts for deciding the time and cost of production, as well as required resources. Fujii and Tanimoto (2004) simulated how architectural environment and human decisions interact by considering the changes in project environment. Sefair et al. (2009) used three decision parameters as environmental impact, design suitability, and cost to evaluate and select best-performing materials.

This study was focused on developing an analytic network process (ANP) decision-making model for the selection of environmentally conscious construction methods. In the following, a review of relevant literature is presented. Then, the development of the ANP model is discussed in detail and followed by a case study. Finally, conclusions, limitations, and recommended future studies are discussed.

\section{Literature review}

\subsection{Analytic Network Process (ANP)}

The selection of proper construction methods is a multiple criteria decision-making (MCDM) problem as it typically involves more than one conflicting objective. MCDM methods have been widely cited in the literature as an ideal method for selecting the most feasible alternative based on a set of criteria (e.g. Rakas et al. 2004) or ranking and assessing certain alternatives to achieve a selection process (e.g. Cheng et al. 2002). One of the most important steps in solving MCDM programs is to determine the tradeoffs or weightings of factors affecting decision-making. A commonly cited approach is to apply the analytical hierarchy process (AHP) (Bishop et al. 2008).

AHP was first introduced as a decision network, which is composed of clusters, their elements, and links between the elements (Saaty 2001). It is known as a useful and flexible decision-making tool, which can help decision-makers set priorities and make the best decision by handling both qualitative and quantitative aspects of a decision (Chen et al. 2005). AHP obtains data by asking experts to input directly or perform pair-wise comparisons (Bishop et al. 2008). It can be used to decide priority of items in a wide range such as ratings for information technologies, state and federal offices, relocation sites, entertainment systems and more (Saaty 2008). Recently, an AHP-based method has been proposed in connection with life cycle assessment (LCA) to compare data quality indicators for three building materials as concrete, steel, and glass (Wang et al. 2012).

Although AHP has been utilized in various areas of construction research and practice since the late 1970s (Zeeger, Rizenbergs 1979), it only allows users to form hierarchical relationships between vertical levels of a decision model. Consequently, it has no parallel connections between decision factors at the same level. It is therefore not possible to hierarchically structure many decision problems because of the need for a network that involves cycles between clusters, as well as loops within the same cluster (Saaty, Vargas 2006).

This shortcoming has been overcome by a different method, that of analytic network process (ANP). This process is more powerful in modelling complex decisionmaking problems than AHP, as interactions and dependencies are often present among levels or within the same level (Saaty 2004). Therefore, Saaty (2001) recommended using ANP when a more comprehensive and systematic analysis is needed. The output from an ANP process is the relative importance weights of various parameters.

ANP has been widely used for project evaluation and selection (e.g. Cheng, Li 2005), project location selection (e.g. Partovi 2006; Tuzkaya et al. 2008), and performance measurement (e.g. Cheng, Li 2005; Ozorhon et al. 2007). In this study, ANP is used to find the relative importance weights of project conditions and resource properties in order to model the decision-making of construction professionals.

\section{Methodology}

The methodology of this study includes the generation of ANP-based decision-making model and using the results of this model to select the most feasible construction method (CM). The flowchart for the decision-making process in this paper is shown in Figure 1. Next sections will give details of the process based on the steps given in this flowchart.

\subsection{Determination of decision factors}

Since the decision model in this study is designed to support the selection of the most feasible $\mathrm{CM}$, project conditions and resource performance indicators associated with the execution of a project are identified as decision factors. For this purpose, the existing literature on this topic has been reviewed and typical project conditions are identified. 


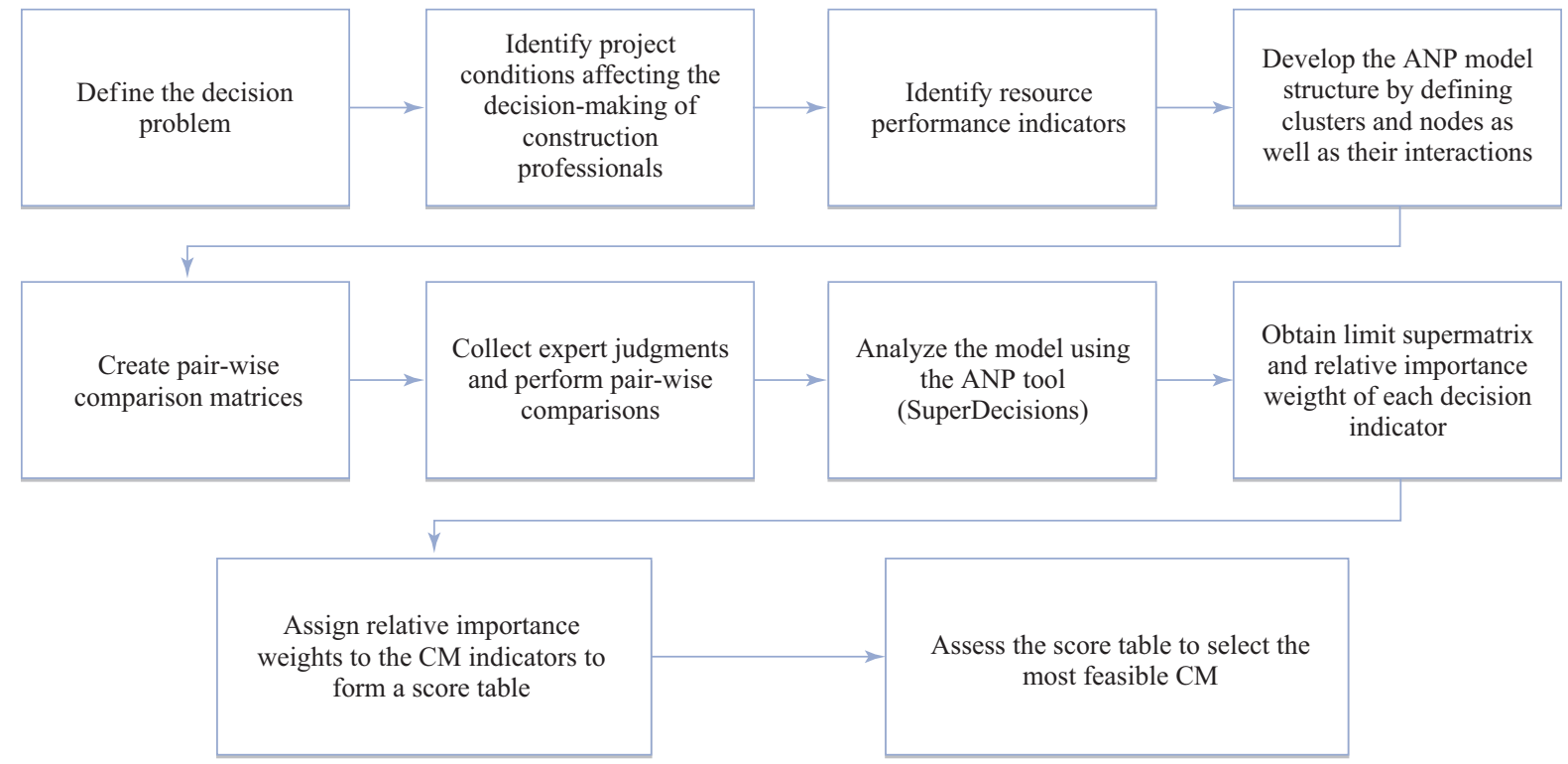

Fig. 1. Flowchart for the decision-making process

Table 1. Project conditions and relevant studies

\begin{tabular}{ll}
\hline Project conditions & \multicolumn{1}{c}{ Studies } \\
\hline & Chan, Kumaraswamy (1996); \\
Unavailability of resources & Rojas, Mukherjee (2003); \\
& Mukherjee et al. (2005); \\
& Assaf, Al-Hejji (2006); \\
& Sun, Meng (2009) \\
\hline & Chan, Kumaraswamy (1996); \\
& Al-Momani (2000); \\
Rejas, Mukherjee (2003); & Mukherjee et al. (2004); \\
& Wu et al. (2004); \\
& Rojas, Mukherjee (2006); \\
& Assaf, Al-Hejji (2006); \\
Arun, Rao (2007)
\end{tabular}

Frimpong et al. (2003);

Increase in unit cost of resources

Mukherjee et al. (2004);

Arain, Pheng (2005);

Rojas, Mukherjee (2006);

Arun, Rao (2007)

Chan, Kumaraswamy (1996);

Al-Momani (2000);

El-Rayes, Moselhi (2001);

Unexpected conditions (e.g. bad weather, labor strike,

Mukherjee, Rojas (2003);

unforeseen ground conditions)

Mukherjee et al. (2004);

Wu et al. (2004);

Assaf, Al-Hejji (2006);

Rojas, Mukherjee (2006)

Chan, Kumaraswamy (1996);

Change in design (e.g. client initiated variations,

Williams (2000);

Wu et al. (2004);

change orders by owner)

Assaf, Al-Hejji (2006);

Sun, Meng (2009)

Hanna et al. (1999);

Adverse financial issues of owner (e.g. changes in cash flow)

Assaf, Al-Hejji (2006);

Sun, Meng (2009)

Adverse market conditions (affecting owner)

Williams (2000);

Arain, Pheng (2005);

Sun, Meng (2009) 
Project conditions that affect the decision-making of construction professionals are defined based on previous studies of highway construction and project changes. Seven conditions that can influence the CM selection, and likewise resource utilization, are selected, including unavailability of resources, delay in resource delivery, increase in unit cost of resources, unexpected conditions (e.g. bad weather, labour strike, unforeseen ground conditions), change in design (e.g. client-initiated variations, change orders by owner), adverse financial issues of owner (e.g. changes in cash flow), and adverse market conditions. Adverse financial issues and adverse market conditions can influence an owner's decision, while the remaining conditions can affect the contractor's decision on construction method selection. These project conditions and relevant studies are shown in Table 1.

In addition to project conditions, resource performance indicators are defined based on the common characteristics of construction operations. Material selection (Flórez, Irizarry 2010), equipment selection (Shapira, Goldenberg 2007), and stabilization performance of the highway (Ozcan-Deniz, Zhu 2011) are selected to reflect the characteristics of construction resource performance. Stabilization performance of the highway refers to the strength and properties of the friction course (FC) which meet the desired or required level of performance for anticipated traffic.

\subsection{Development of the ANP-based decision-support model}

The ANP-based decision-support model can be constructed by using four main steps, including 1) ANP model structure, 2) preparation of pair-wise comparison matrices, 3) supermatrix formation, and 4) determination of the relative importance weight of each decision factor.

\subsubsection{ANP model structure}

Typically, a decision problem is identified and decomposed into a set of manageable and measurable levels. An

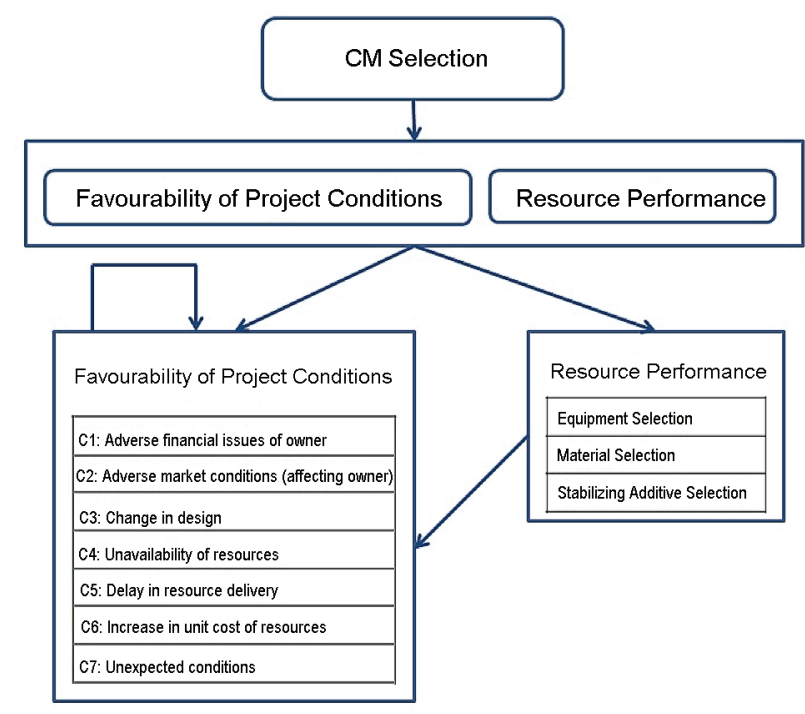

Fig. 2. ANP decision model constructed with Super Decisions
ANP model is mainly composed of two parts, a control hierarchy that controls a network of influences among clusters and nodes at different levels of a system, and interactions between different clusters and nodes (interdependencies and feedback). Thus, a decision problem is defined in the form of clusters, nodes, and the relationships between them. Figure 2 shows a decision model constructed using SuperDecisions software for selecting construction methods.

The control hierarchy starts from the top-most level, defining the goal of a decision problem (Saaty 1980). The goal of a decision problem is usually decomposed into determinants (clusters). In this case, the selection of construction methods is determined by two clusters: favourability of project conditions and resource performance. The clusters are then further decomposed into attributes (nodes). Project conditions from $\mathrm{C} 1$ to $\mathrm{C} 7$ are nodes defining the first cluster, i.e. favourability of project conditions, while material selection, equipment selection, and stability additive selection are nodes used to define the other cluster, resource performance.

To form a network of influences, ANP allows dependencies to be modelled both within a cluster (inner dependence) and between clusters (outer dependence) (Saaty 2001). Arrows in Figure 2 indicate interactions (i.e. interdependencies and feedback) within clusters, as well as between clusters and nodes. The arrows are drawn from a parent component to child components. The parent component bears a control criterion for comparing two or more child components. For example, in Figure 2, CM Selection is the parent component for Favourability of Project Conditions and Resource Performance. Thus, the favourability of project conditions and resource performance are compared with respect to $\mathrm{CM}$ selection criteria. This type of straight arrow shows outer dependencies among clusters, as well as among nodes. On the other hand, loop arrows that start from and finish on the same cluster stand for inner dependencies within a cluster. For instance, the loop arrow for the favourability of project conditions shows that some of the project conditions affect others that are in the same cluster. The inner dependence regarding favourability of project conditions is based on the effect of Owner in decisionmaking. The influence of Owner on the decision-making of the Contractor is reflected through Change in Design, which is the reason of the inner dependence in this cluster.Since there is no inner dependence in the Resource Performance cluster, there is no loop arrow starting from and finishing on this cluster.

In order to represent the relationship between project conditions and resource performance indicators, certain abbreviations and equations are used. Project conditions are connected to each resource performance indicator separately. Figure 3 shows the relationship between project conditions and material selection. As given in Figure 3, each condition is described by its relative importance weight (IW) of materials and probability of occurrence (P). IWs and Ps are represented by the numbers 


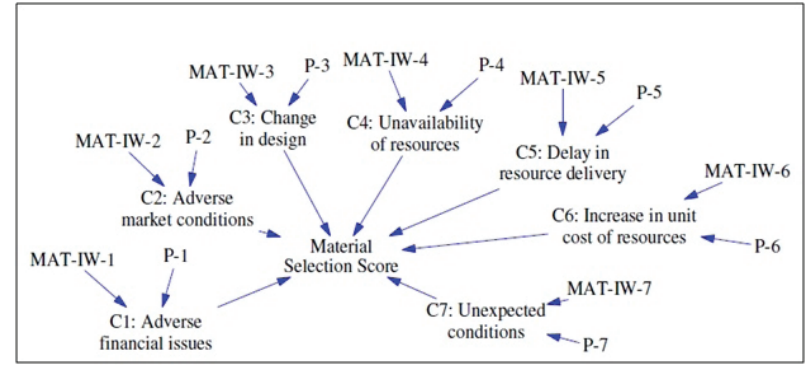

Fig. 3. Relations between project conditions and material selection

of their project conditions. For example, IW-1 corresponds to the relative importance weight of $\mathrm{C} 1$, while $\mathrm{P}-1$ corresponds to the probability of occurrence of $\mathrm{C} 1$. IWs are obtained from the results of the ANP analysis. As ANP analysis outputs IW values differently for material, equipment, and stabilizing additive selection, the abbreviations of relative importance weights for these three parameters are presented differently. Relative importance weights regarding material selection are shown as MAT-Ci, while relative importance weights for equipment selection are given as EQUIP-Ci, and for stabilizing additive selection are shown as STAB-Ci, where " $\mathrm{i}$ " is the condition number from 1 to 7 .

Probabilities (Ps) are user-defined inputs. The probability of occurrence of conditions is not different for different material, equipment, or stabilizing additive.
Therefore, when probabilities are entered, they are used to calculate scores for all resource performance indicators. The relationship between project conditions and resource performance indicators are shown connected to the $\mathrm{CM}$ Selection in Figure 4. In order to be able to proceed with the $\mathrm{CM}$ selection and the equations of the model, the next section will give details about the relative importance weight calculations with the ANP analysis.

\subsubsection{Pair-wise comparison matrices}

Pair-wise comparison matrices are developed based on the ANP decision model structure (Fig. 2). The pair-wise comparison is usually handled in a matrix format where diagonal cells contain 1 , suggesting equal importance between components on the corresponding row and column. Then, the top triangle is used to enter the scores for each row-column component pair and their reciprocal values are automatically assigned to the reverse triangle within the matrix. When pair-wise comparisons are completed, the relative importance values are used to calculate the eigenvector of each of the constructed matrices. Next, the consistency of judgment needs to be computed, as it can be a problem during the ANP process. The consistency ratio provides a numerical assessment of how inconsistent the evaluations might be. It can be calculated by using Eqn (1). Saaty (1994) set three acceptable levels for consistency: 0.05 for a 3 by 3 matrix, 0.08 for a 4 by 4 matrix, and 0.10 for other matrices:

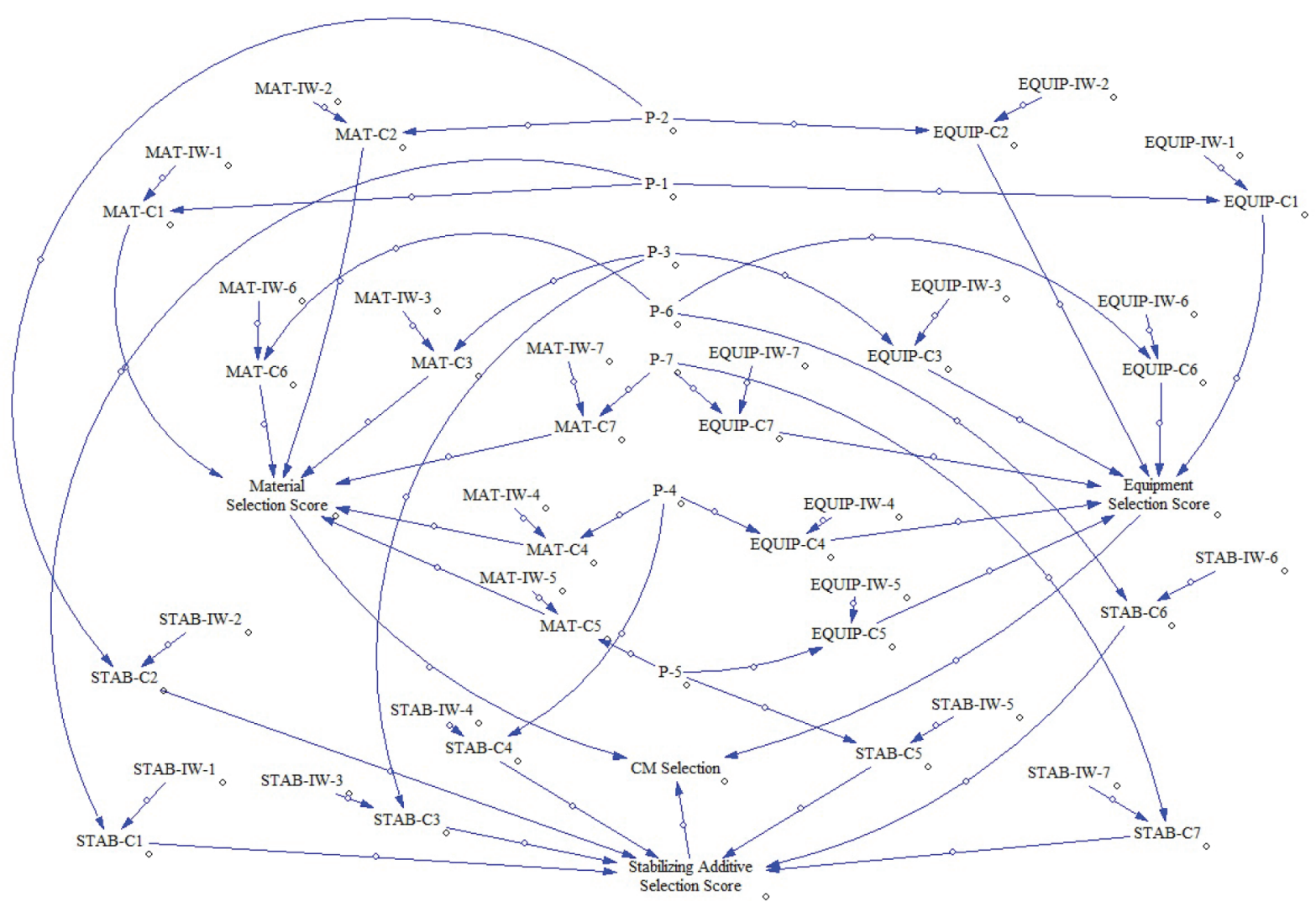

Fig. 4. Relations between project conditions and resource performance indicators 


$$
C I=\frac{\lambda_{\max }-n}{n-1}
$$

where $\lambda_{\max }$ is the largest eigenvalue and $\mathrm{n}$ is the number of evaluations.

Structured interviews of highway resurfacing construction professionals were conducted to gain their perspectives on decision-making under the influence of certain project conditions. The experts were asked to fill the pairwise comparison matrices by using a nine-point priority scale (Saaty 1980). Six interviews were conducted with professionals. Although there is no minimum number of interviews required for ANP in the literature, it is common to use three or more experts to generate an ANP decision model (e.g. Dikmen et al. 2010). It can be stated that the consistency of interviews in this study was found satisfactory to fulfil the principles of this research, as the consistency values were smaller than 0.10 , as set by Saaty (1994).

In this study, experts were asked to fill seven comparison matrices by using the nine-point priority scale in Table 2. They compared components in pairs and assigned numbers on a 1-9 scale. All matrices used in the interview were derived from the model structured in Figure 2. The list of matrices is given below:

1. Relative importance weight of favourability of project conditions and resource performance with respect to CM selection;

2. Relative importance weight of project conditions with respect to favourability of project conditions;

3. Relative importance weight of resource performance indicators with respect to resource performance;

4. Relative importance weight of $\mathrm{C} 1$ : Adverse financial issues of owner and $\mathrm{C} 2$ : Adverse market conditions (affecting owner) with respect to $\mathrm{C} 3$ : Change in design;

5. Relative importance weight of project conditions with respect to material selection;

6. Relative importance weight of project conditions with respect to equipment selection;

7. Relative importance weight of project conditions with respect to stabilizing additive selection.
The staticizedgroups method is used to aggregate the judgment of an individual expert. The technique was described as the Delphi method with one round of estimates (Dayananda et al. 2002). Hallowell and Gambatese (2010) defined staticized groups as an alternative to the Delphi method without feedback or iteration.

Two examples of the ANP pair-wise comparison matrices are shown in Table 3 and Table 4. The first matrix is an example of outer dependence between two clusters, one of the CM selection determinant (level 2) and favourability of project conditions (level 3), while the second matrix serves as an example of the inner dependence within the favourability of project conditions cluster. The remaining pair-wise comparison matrices are also completed by construction professionals in the same manner. Consistency ratios were found to be less than 0.10 .

\subsubsection{Supermatrix formation}

After the level of consistency is satisfied for each matrix, the seven matrices are combined to form a supermatrix (Saaty 2001). There is a three-step procedure in supermatrix calculation (Saaty 2001). The first step is composed of calculating an unweighted supermatrix directly from pair-wise comparisons among components affecting each other. The second step includes generating the weighted supermatrix by considering the interactions between the clusters of components, then normalizing the weighted supermatrix by making it column stochastic, i.e. sum of the column values adding up to 1 . The third step is generating the limit supermatrix by raising the weighted supermatrix to powers until it converges and remains stable.

For the purpose of computing the supermatrix, the commercially available software Super Decisions was used in this study. Super Decisions was developed by William J. Adams of Embry Riddle Aeronautical University and Rozann W. Saaty (Saaty 2003). The supermatrix generated by the software gives the relative importance weights of clusters and nodes in a tabular form, so that the magnitude of influence of each node on the decision problem is obtained.

Table 2. Nine-point priority scale for ANP

\begin{tabular}{cll}
\hline $\begin{array}{l}\text { Intensity of } \\
\text { importance }\end{array}$ & \multicolumn{1}{c}{ Definition } & \multicolumn{1}{c}{ Explanation } \\
\hline 1 & Equal importance & $\begin{array}{l}\text { Two activities (row and column components) contribute equally to the } \\
\text { objective }\end{array}$ \\
\hline 3 & Moderate importance & $\begin{array}{l}\text { Experience and judgment slightly favor one (row component) over another } \\
\text { (column component) }\end{array}$ \\
\hline 7 & Strong importance & $\begin{array}{l}\text { Experience and judgment strongly favor one (row component) over another } \\
\text { (column component) }\end{array}$ \\
\hline 9 & Eery strong importance & $\begin{array}{l}\text { An activity (row component) is strongly favored over another (column } \\
\text { component), and its dominance is demonstrated in practice }\end{array}$ \\
\hline $2,4,6,8$ & Intermediate values & $\begin{array}{l}\text { The evidence favoring one activity over another is of the highest possible } \\
\text { order of affirmation, i.e. overwhelming dominance of an activity (row } \\
\text { component) is over another (column component) }\end{array}$ \\
\hline
\end{tabular}


Table 3. Relative importance weight of project conditions with respect to favourability of project conditions

\begin{tabular}{|c|c|c|c|c|c|c|c|}
\hline Favourability of project conditions & $\mathrm{C} 1$ & $\mathrm{C} 2$ & $\mathrm{C} 3$ & $\mathrm{C} 4$ & $\mathrm{C} 5$ & C6 & $\mathrm{C} 7$ \\
\hline $\mathrm{C} 1$ : Adverse financial issues of owner & 1 & 7 & 7 & 7 & 3 & 1 & 7 \\
\hline C2: Adverse market conditions (affecting owner) & $1 / 7$ & 1 & 7 & 7 & 3 & 1 & 7 \\
\hline C3: Change in design & $1 / 7$ & $1 / 7$ & 1 & $1 / 5$ & $1 / 7$ & 1 & 5 \\
\hline C4: Unavailability of resources & $1 / 7$ & $1 / 7$ & 5 & 1 & 1 & 5 & 7 \\
\hline C5: Delay in resource delivery & $1 / 3$ & $1 / 3$ & 7 & 1 & 1 & 5 & 6 \\
\hline C6: Increase in unit cost of resources & 1 & 1 & 1 & $1 / 5$ & $1 / 5$ & 1 & 2 \\
\hline C7: Unexpected conditions & $1 / 7$ & $1 / 7$ & $1 / 5$ & $1 / 7$ & $1 / 6$ & $1 / 2$ & 1 \\
\hline
\end{tabular}

Table 4. Relative importance weight of $\mathrm{C} 1$ : adverse financial issues of owner and $\mathrm{C} 2$ : adverse market conditions (affecting owner) with respect to $\mathrm{C} 3$ : change in design

\begin{tabular}{lcc}
\hline C3: Change in design & $\begin{array}{c}\text { C1: Adverse } \\
\text { financial } \\
\text { issues of } \\
\text { owner }\end{array}$ & $\begin{array}{c}\text { C2: Adverse } \\
\text { market } \\
\text { conditions } \\
\text { (affecting } \\
\text { owner) }\end{array}$ \\
\hline $\begin{array}{l}\text { C1: Adverse financial issues } \\
\text { of owner }\end{array}$ & 1 & 5 \\
\hline $\begin{array}{l}\text { C2: Adverse market } \\
\text { conditions (affecting owner) }\end{array}$ & $1 / 5$ & 1 \\
\hline
\end{tabular}

The limit supermatrix is shown in Table 5. The table gives information about the pair-wise comparison as well as the comparison between levels of the ANP model. The intersection of two components (one in row and the other in column) gives an idea about the percentage of relative importance between these components. For example, it can be seen that C3: Change in design is affected by $\mathrm{C} 1$ : Adverse financial issues of owner around 17\% (as given at the intersection of $\mathrm{C} 1$ : Adverse financial issues of owner row and C3: Change in design column), and by $\mathrm{C} 2$ : Adverse market conditions around $83 \%$ (as given at the intersection of $\mathrm{C} 2$ : Adverse market conditions row and C3: Change in design column). If no relationship is set between two components, a value of zero is obtained at the intersection. For instance, there is no relationship set between $\mathrm{C} 1$ : Adverse financial issues of owner and $\mathrm{C} 2$ : Adverse market conditions; i.e. the intersection of $\mathrm{C} 1$ : Adverse financial issues of owner row and $\mathrm{C} 2$ : Adverse market conditions column (or vice versa) is $0 \%$.

\subsubsection{The relative importance weights of clusters and nodes}

The last step is to derive the relative importance weight of each node and cluster for construction method selection based on the limit supermatrix. The limit supermatrix presents results in a tabular form, which contains relative importance weights as priorities for all nodes in the model. The priorities are also available as normalized by cluster, i.e. priorities sum up to 1 in each cluster. The results obtained from the limit supermatrix table can be organized in different ways. The relative importance weights of clusters that are extracted from the limit supermatrix are shown in Table 6. Table 6 can be used to determine which one of the clusters, project conditions, or resource performance indicators is most important in the CM selection. Considering the results in Table 6, resource performance indicators are rated as more important (around 75\%) than favourability of project conditions (around 25\%) in selecting the most feasible construction method.

Another part of the limit supermatrix is used to derive the relative importance weights of nodes, as shown in Table 7. By using Table 7, a comparison between each project condition and resource performance indicator can be performed. Among project conditions given in Table 7, delay in resource delivery $(10 \%)$ has the highest rank. This implies the importance of meeting the deadline in highway construction projects. The time objective was also mentioned by the experts during their interviews. They stated that the need to finish on time was crucial as the closure of lanes could cause serious traffic problems. Furthermore, the ANP results are shown to support these concerns. Following delay in resource delivery, unavailability of resources $(8.8 \%)$ has the second highest score in project conditions. The result suggests that the timely delivery of resources to the site has the priority for contractors. Next, the item that ranked third in project conditions is adverse financial issues of owner $(8.3 \%)$, which directly affects the cash flow and the work capacity of a contractor. Finally, increase in unit cost of resources $(1.4 \%)$ is found to be the least important in the cluster. The reason for this may be the reflection of unit cost increase in the total bid amount. In this way, the contractor is paid by the increased unit cost amount, and he/she does not experience any significant problem in his/her finances.

When a resource performance indicators cluster is considered, stabilizing additive selection $(14.6 \%)$ is significantly more important in the cluster. There can be two 


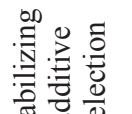

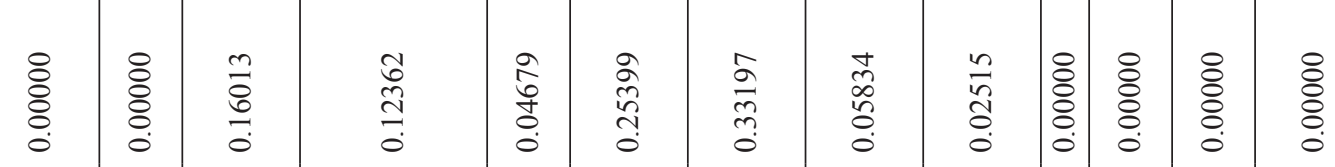

$\cdot \frac{\pi}{0} \cdot \frac{0}{0}$

¿े

$m$
0
0
0
0

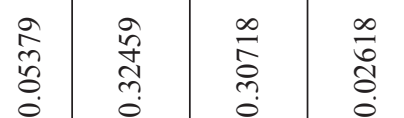

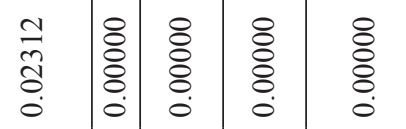

节

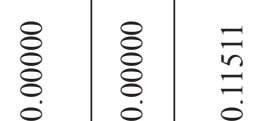

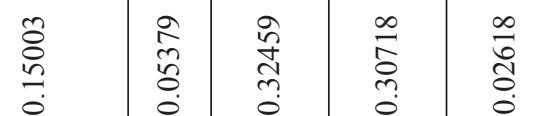

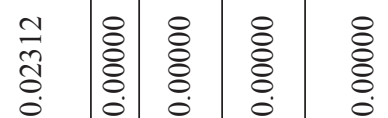

$\sum \frac{\substack{0 \\ \hline}}{\frac{0}{0}}$

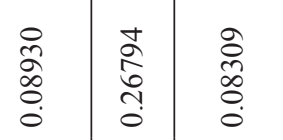

$\stackrel{2}{\frac{2}{0}}$

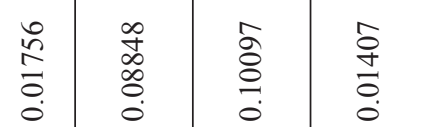

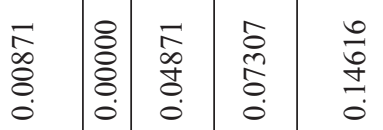

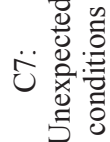

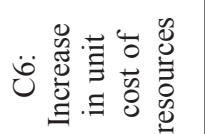

\begin{tabular}{l|l|l} 
& & \\
0 & 0 & 8 \\
0 & 0 & 0 \\
0 & 0 & 0 \\
0 & 0 & 0 \\
0 & 0
\end{tabular}

\&̊

\begin{tabular}{ll|l} 
& & \\
8 & 8 \\
$\vdots$ & $\vdots$ \\
0 & 0 \\
0 & 0
\end{tabular}

8
$\vdots$
$\vdots$
0

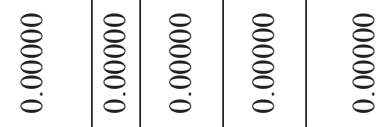

\begin{tabular}{l|l|l} 
& & \\
8 & 8 & 8 \\
0 & 0 & 0 \\
0 & 0 & 0 \\
0 & 0 & 0
\end{tabular}

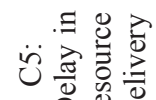

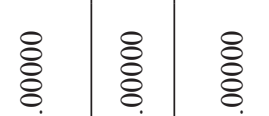

ஓ̊.

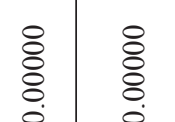

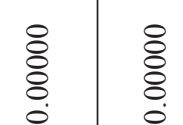

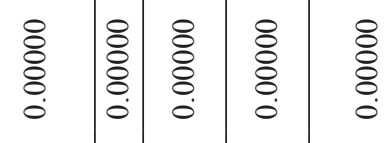

ஓे

\begin{tabular}{ll|l}
8 & & 8 \\
8 & 0 \\
0 & 0 \\
0 & 0 \\
0 & 0
\end{tabular}

\&े छ

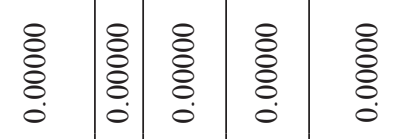

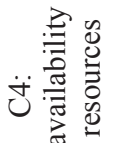

苛嵌

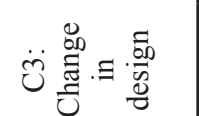

\begin{tabular}{l|l|l}
0 & 0 & 8 \\
$\vdots$ & $\vdots$ & $\vdots$ \\
$\vdots$ & 0 & $\vdots$ \\
0 & 0 & 0 \\
0 & 0 & 0
\end{tabular}

8
$\vdots$
0
0

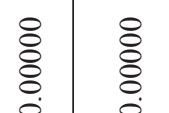

๕.

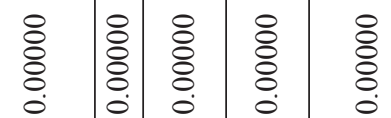

$m$
$m$
$\infty$
0
0

\begin{tabular}{cc|}
0 & 0 \\
$\vdots$ & 0 \\
$\vdots$ & 0 \\
0 & 0 \\
0 & 0
\end{tabular}

@

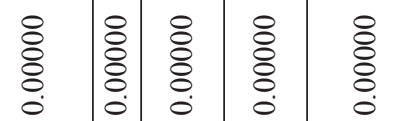

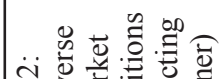

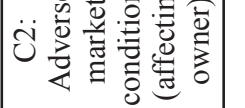

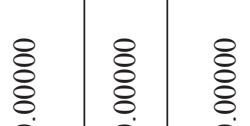

ڤ̊.

\begin{tabular}{ll|l} 
& & \\
8 & 8 \\
$\vdots$ & 8 \\
0 & 0 \\
0 & 0 \\
0 & 0
\end{tabular}

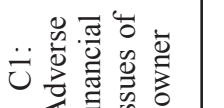

\begin{tabular}{l|l|l}
$\circ$ & 0 & 0 \\
$\vdots$ & 0 & 0 \\
0 & 0 & 0 \\
0 & 0 & 0 \\
0 & 0 & 0
\end{tabular}

@̊̀.

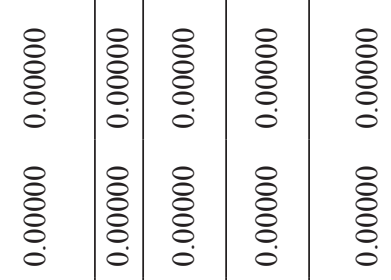

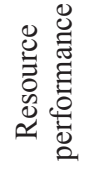

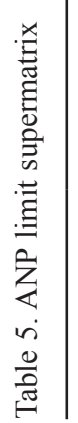

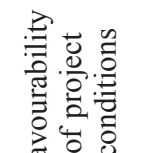

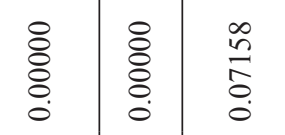

$\infty$
$\stackrel{2}{o}$
0
0

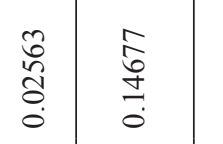

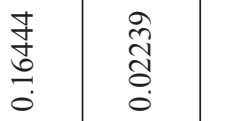

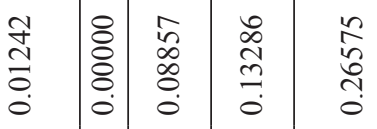

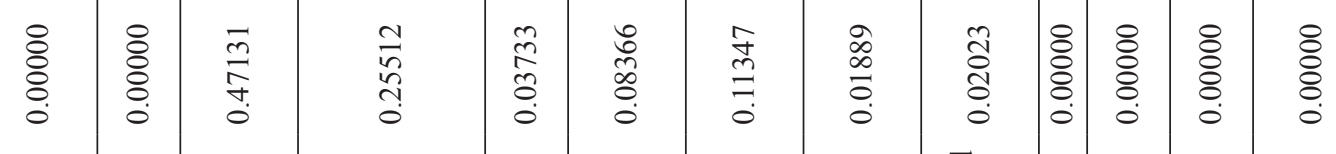

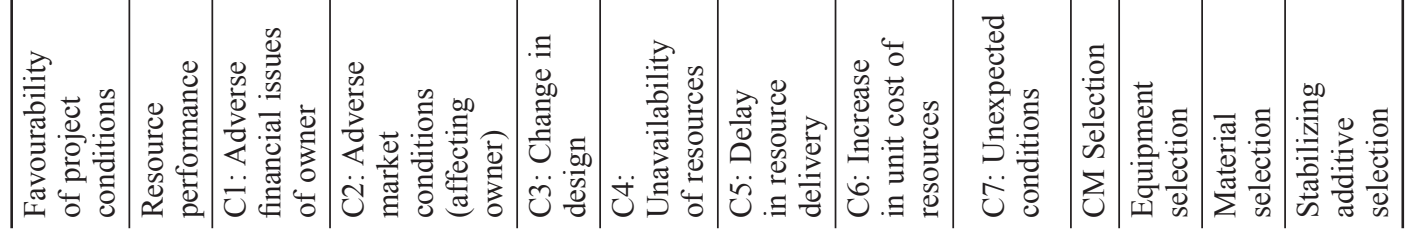


Table 6. Relative importance weights of clusters

\begin{tabular}{llc}
\hline Cluster & \multicolumn{1}{c}{ Node } & $\begin{array}{c}\text { Relative importance } \\
\text { weights }\end{array}$ \\
\hline CM & $\begin{array}{l}\text { Favourability of } \\
\text { project conditions }\end{array}$ & 0.24998 \\
\cline { 2 - 3 } Selection & Resource performance & 0.75002 \\
\hline
\end{tabular}

Table 7. Relative importance weights of nodes in the limit supermatrix

\begin{tabular}{lc}
\hline Node & $\begin{array}{c}\text { Relative importance } \\
\text { weights }\end{array}$ \\
\hline C1: Adverse financial issues of owner & 0.083091 \\
\hline $\begin{array}{l}\text { C2: Adverse market conditions } \\
\text { (affecting owner) }\end{array}$ & 0.061932 \\
\hline C3: Change in design & 0.017561 \\
\hline C4: Unavailability of resources & 0.088482 \\
\hline C5: Delay in resource delivery & 0.100966 \\
\hline C6: Increase in unit cost of resources & 0.014068 \\
\hline C7: Unexpected conditions & 0.008708 \\
\hline Equipment selection & 0.048714 \\
\hline Material selection & 0.073073 \\
\hline Stabilizing additive selection & 0.146155 \\
\hline
\end{tabular}

reasons for this result. The first one can be the limitation of contractors in material and equipment selection. If contractors are expected to use certain types of material and equipment, such as the ones stated in the contract, they may give a higher score to stabilizing additive since it is the only parameter they can control. The second reason is that the stabilizing additive is used to determine the durability of the highway. Therefore, this item may be ranked higher than material and equipment selection (7.3\% and $4.9 \%$, respectively).

The limit supermatrix results show the relative importance of each node regardless of their cluster. The results suggest that the resource performance indicators have a considerable influence on the $\mathrm{CM}$ selection process. The high score of resource performance indicators is caused by the effect of stabilizing additive selection, which is ranked as the second most important node in Table 7. It is followed by delay in resource delivery. As expected, the importance degrees of nodes in project conditions and resource performance indicators clusters match the rank of the ones in Table 6. The matching rankings of nodes in each cluster and in the limit supermatrix suggest the consistency of ANP results. It should also be noted that these results reflect the subjective judgments of a number of highway construction professionals. Thus, the study is limited to the experience of experts involved in the interview process.

Additionally, the relative importance weights of project conditions regarding material, equipment, and stabilizing additive selection are given in Table 8. As it can be observed from the table, the relative importance weights of equipment and material selection with regard to the project conditions output equal values. The main reason for this result is caused by the experts' input during the interviews. The experts gave the same importance to material and equipment selection for highway construction projects. During the interviews, they have explained this situation by evaluating material and equipment as complimentary to each other. For example, when a material is selected, the selection of the proper equipment to use with that material is considered as important as the material itself. Therefore, the relative importance weights regarding equipment and material output the same values in the limit supermatrix. On the other hand, stabilizing additive selection is rated slightly more important than material and equipment selection regarding its effect on highway durability. The relative importance values will be used to select each resource performance indicator by using the score table. The details of the CM selection by using the score table will be explained in the next section.

\section{Case study}

\subsection{Score table for the selection of the most feasible construction method}

The relative importance weights obtained in Table 8 were assigned to the project conditions for each resource performance indicator. For each condition, the score was calculated by multiplying its relative importance weight and probability. Relative importance weights are the results of the ANP analysis, while probabilities are user inputs obtained from the interviews. Both the probabilities and the relative importance weights are used to form a score table for each resource performance indicator. An example material score for project condition-1 is shown in Eqn (2). In this equation, material score "MAT-Ci" is calculated by multiplying relative importance weight "MAT-IW-i" and probability "P-i" of project condition-i. For example, to calculate material score for the first project condition "MAT-C1", relative importance weight "MAT-IW-1" and probability "P-1" of project condition-1 are multiplied. The relative importance weight "MAT-IW-1" is given as 0.11511 in Table 8 . This procedure was repeated for seven conditions. The relative importance weights given in Table 8 are used to calculate the score of project conditions for material, equipment, and stabilizing additive selection, as given in Eqns (2)-(4). Then, the scores of project conditions were combined for each resource performance indicator. The equations for the resource performance indicators as obtained from the scores of the seven conditions are given in Eqns (5), (6), and (7).

$$
\text { "MAT }-\mathrm{Ci} "=\text { "MAT }-\mathrm{IW}-\mathrm{i} " * \text { "P -i", }
$$

where: MAT-Ci is the material score of condition i (Ci); MAT-IW-i is the material importance weight of $\mathrm{Ci}$; and $\mathrm{P}-\mathrm{i}$ is the probability of occurrence of $\mathrm{Ci}$.

$$
\text { "EQUIP - Ci" = "EQUIP - IW - i"*"P-i", }
$$


Table 8. Relative importance weights of project conditions

\begin{tabular}{lccl}
\hline & $\begin{array}{c}\text { Equipment } \\
\text { selection }\end{array}$ & $\begin{array}{c}\text { Material } \\
\text { selection }\end{array}$ & $\begin{array}{c}\text { Stabilizing } \\
\text { additive } \\
\text { selection }\end{array}$ \\
\hline C1: Adverse financial issues of owner & 0.11511 & 0.11511 & 0.16013 \\
\hline C2: Adverse market conditions (affecting owner) & 0.15003 & 0.15003 & 0.12362 \\
\hline C3: Change in design & 0.05379 & 0.05379 & 0.04679 \\
\hline C4: Unavailability of resources & 0.32459 & 0.32459 & 0.25399 \\
\hline C5: Delay in resource delivery & 0.30718 & 0.30718 & 0.33197 \\
\hline C6: Increase in unit cost of resources & 0.02618 & 0.02618 & 0.05834 \\
\hline C7: Unexpected conditions & 0.02312 & 0.02312 & 0.02515 \\
\hline
\end{tabular}

where: EQUIP-Ci is the equipment score of condition $\mathrm{i}(\mathrm{Ci})$; EQUIP-IW-i is the equipment importance weight of $\mathrm{Ci}$; and $\mathrm{P}-\mathrm{i}$ is the probability of occurrence of $\mathrm{Ci}$.

$$
\text { “STAB-Ci” = "STAB-IW-i”*”P-i”, }
$$

where: STAB-Ci is the stabilizing additive score of condition i (Ci); STAB-IW-i is the stabilizing additive importance weight of $\mathrm{Ci}$; and $\mathrm{P}-\mathrm{i}$ is the probability of occurrence of $\mathrm{Ci}$.

$$
\begin{aligned}
& \text { Material Selection Score = "MAT-C1" + } \\
& \text { "MAT-C2" + "MAT-C3" + "MAT-C4"+ } \\
& \text { "MAT-C5" + "MAT-C6" + "MAT-C7"; }
\end{aligned}
$$

Equipment Selection Score = "EQUIP-C1" + "EQUIP-C2" + "EQUIP-C3" + "EQUIP-C4" +

"EQUIP-C5" + "EQUIP-C6" + "EQUIP-C7";

Stabilizing Additive Selection Score $=$ "STAB-C1" + "STAB-C2" + "STAB-C3" + "STAB-C4" +$$
\text { "STAB-C5" + "STAB-C6" + "STAB-C7". }
$$

The CM selection score table was formed for each resource performance indicator by using the material, equipment, and stabilizing additive scores and types. First, boundary conditions are defined and entered as a range of scores. For five types of materials, five ranges with min 0 , max 100 and increments of 20 are defined, as given in Table 9. By using the equations, the weighted total for each material type was calculated and the material types were ranked according to their weighted performance on project success. The materials from best performing to least performing were obtained as Hot In-Place (HIP) mix, Superpave, recycled Hot Mix Asphalt (HMA), virgin HMA, and virgin Warm Mix Asphalt (WMA). The increment [0-19] is assigned to the least performing material, while the increment [80-100] is assigned to the best performing one. The top boundary is set to 100 , as the overall material score is estimated based on this denominator.

Secondly, the relative importance weights are multiplied with the probabilities and summed up to the over-
Table 9. The CM selection score table for materials

\begin{tabular}{lcc}
\hline Rank of materials & $\begin{array}{c}\text { Range of } \\
\text { scores }\end{array}$ & $\begin{array}{c}\text { Code of } \\
\text { material } \\
\text { type }\end{array}$ \\
\hline Hot In-Place (HIP) mix & $80-100$ & 5 \\
\hline Superpave & $60-79$ & 4 \\
\hline $\begin{array}{l}\text { Recycled Hot Mix Asphalt } \\
\text { (HMA) }\end{array}$ & $40-59$ & 2 \\
\hline Virgin HMA & $20-39$ & 1 \\
\hline $\begin{array}{l}\text { Virgin Warm Mix Asphalt } \\
\text { (WMA) }\end{array}$ & $0-19$ & 3 \\
\hline
\end{tabular}

all material selection score by using Eqn (5), which is matched with the range of scores. The code of material type is obtained according to the proper range and then, the type of material is selected by using IF-THEN rules. As an example, if the material score is obtained as 85 from Eqn (5), then this value is used in Figure 5, and Number 5, which is Hot In-Place (HIP) mix, is selected as the material type.

The definition of boundary conditions and selection procedures for equipment and stabilizing additive are performed in the same manner. The CM score table is created in the form of the IF-THEN rules, as given in Eqns (9), (10), (11), and (12) for each project, where Mi is the $\mathrm{i}^{\text {th }}$ material, $\mathrm{Ei}$ is the $\mathrm{i}^{\text {th }}$ equipment, and $\mathrm{Si}$ is the $i^{\text {th }}$ stabilizing additive type. The rules are entered into the decision-making system to select the most feasible

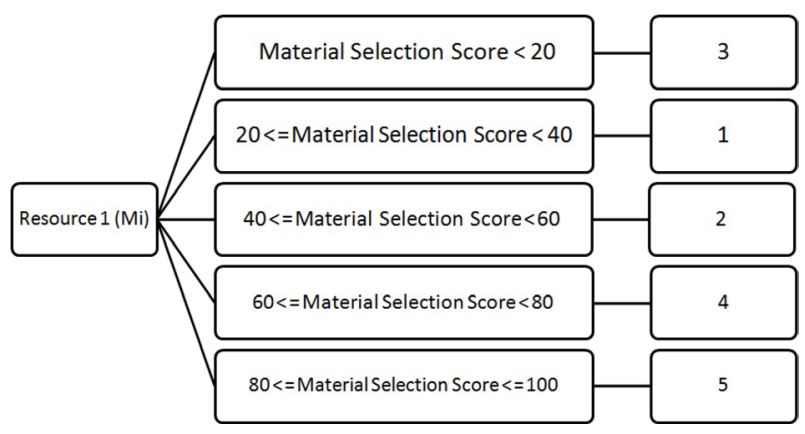

Fig. 5. IF-THEN rules for material selection 
construction method. For example, assuming Superpave asphalt falls between boundaries [40, 60], IF the material score is 50, THEN the system selects Superpave asphalt for the paving activity. Similar IF-THEN rules and boundary conditions are also followed for the equipment and stabilizing additive selection.

$$
\mathrm{CMi}=\{\mathrm{Mi}, \mathrm{Ei}, \mathrm{Si}\}
$$

IF Material Score $=$ Y,

THEN select Mi, where $i \in[0,5]$;

IF $\mathrm{Mx}=$ Mi \& Equipment Score $=\mathrm{Z}$,

THEN select Ei, where $i \in[0,2]$;

IF Mx $=$ Mi \& Ex $=$ Ei \& Stabilizing Additive Score $=K$, THEN select $\mathrm{Si}$, where $\mathrm{i} \in[0,2]$.

\subsection{Analysis of the model}

The CM selection model is tested using a case study. The case study is a resurfacing project from the Florida Department of Transportation (FDOT). The project includes activities such as milling existing asphalt, placing asphaltic concrete pavement, and adding a concrete friction course. The resurfacing operation is performed lane by lane. In the conventional method, the existing asphalt is milled and hauled by dump trucks to be recycled. The new asphaltic concrete to be placed can be a virgin or recycled mix. An asphalt composition shows differences not only in terms of recycled concrete amount, but also at its temperature of mixing. Three activities are performed in finish-to-start relationships following sections of the highway. An example schedule is shown for a project with three sections in Figure 6. Originally, milling is performed with conventional equipment, and the milled asphalt is hauled by dump trucks to an off-site plant for recycling. Superpave asphalt is used in paving, while FC-5 is used for the friction course layer. In addition to the original construction method, this research sought other appropriate construction methods and new technologies for highway construction, generating 16 construction alternatives for the same project. The alternatives are shown in Table 10.
Among the many mix design methods, Marshall and Hveem are the two most widely accepted for Hot Mix Asphalt (HMA) (Bahia 1993). Although the Marshall mix design method is used by DOTs throughout the U.S., some downsides have been shown in its performance. The Strategic Highway Research Program (SHRP) has thus developed a performance-based asphalt binder and asphalt mix specifications (Roberts et al. 2002). The development of performance graded (PG) binder specifications and tests, resulted in Superpave, an acronym for superior performing asphalt pavements (Larsen 2003).

In addition to the progress in asphalt mix design, the equipment technology has evolved for better milling and asphalt placing performance. Hot In-Place (HIP) recycling technology has been proposed to combine milling the existing asphalt and placing asphaltic concrete activities in resurfacing projects. The new technology has a single unit for recycling the existing pavement and mixing the milled pavement with new paving materials. In this way, HIP eliminates the hauling and handling of the HMA recycled from milling (Russell et al. 2010).

Regarding equipment, the evolution in the industry is based not only on technology, but also fuel type and use. Low-carbon or biofuels, which are mostly derived by soybeans, are promising strategies to reduce life cycle GHG emissions (EPA 2009).

As mentioned before, the differences among alternatives were reflected by different types of materials, equipment, and the stabilizing additive content of materials. In order to calculate material, equipment, and stabilizing additive selection scores, the results of ANP analysis (the relative importance weights) and the probabilities are input to the model. The relative importance weights are given in Table 8, while a random set of probabilities are shown in Table 11. When material, equipment, and stabilizing additive selection scores are calculated, they are entered to the CM selection score table. Then, IF-THEN rules are used to decide on the material, equipment, and stabilizing additive type for the current project.

The combination of different types of material, equipment, and stabilizing additive enables the running

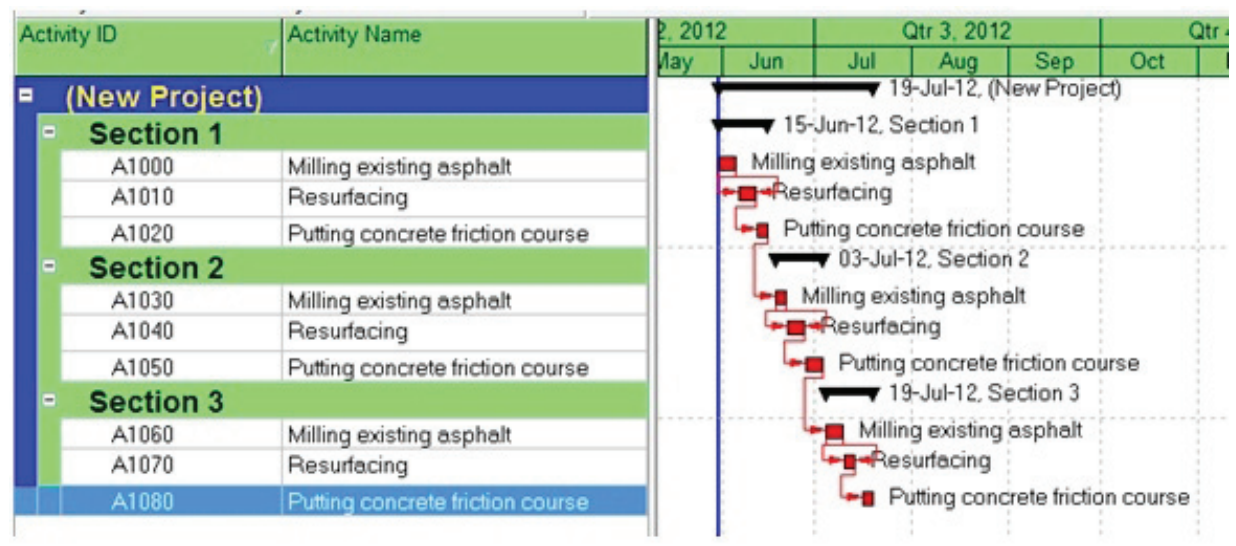

Fig. 6. Example schedule for a resurfacing project 
Table 10. Construction alternatives for resurfacing

\begin{tabular}{llll}
\hline \multicolumn{4}{c}{ Construction methods } \\
\hline No. & \multicolumn{1}{c}{ Resurfacing } & \multicolumn{1}{c}{ Milling } & Friction Course \\
\hline CM1 & Virgin-Conventional HMA & Conventional equipment & FC-5 \\
\hline CM2 & Virgin-Conventional HMA & Biodiesel equipment & FC-5 \\
\hline CM3 & Recycled-Conventional HMA & Conventional equipment & FC-5 \\
\hline CM4 & Recycled-Conventional HMA & Biodiesel equipment & FC-5 \\
\hline CM5 & Virgin-WMA & Conventional equipment & FC-5 \\
\hline CM6 & Superpave & Conventional equipment & FC-5 \\
\hline CM7 & HIP Mix (Marshall+milled) & H.I.P.'s equipment & FC-5 \\
\hline CM8 & HIP Mix (Marshall+milled) & HIP Biodiesel & FC-5 \\
\hline CM9 & Virgin-Conventional HMA & Conventional equipment & FC-9.5 \\
\hline CM10 & Virgin-Conventional HMA & Biodiesel equipment & FC-9.5 \\
\hline CM11 & Recycled-Conventional HMA & Conventional equipment & FC-9.5 \\
\hline CM12 & Recycled-Conventional HMA & Biodiesel equipment & FC-9.5 \\
\hline CM13 & Virgin-WMA & Conventional equipment & FC-9.5 \\
\hline CM14 & Superpave & Conventional equipment & FC-9.5 \\
\hline CM15 & HIP Mix (Marshall+milled) & H.I.P.'s equipment & FC-9.5 \\
\hline CM16 & HIP Mix (Marshall+milled) & HIP Biodiesel & FC-9.5 \\
\hline
\end{tabular}

Table 11. Probabilities used to analyse the case study

\begin{tabular}{|c|c|c|c|c|c|c|c|}
\hline $\begin{array}{c}\text { Trial } \\
\#\end{array}$ & P-1 & P-2 & P-3 & P-4 & P-5 & P-6 & P-7 \\
\hline 1 & 0.63 & 0.61 & 0.35 & 0.51 & 0.99 & 0.10 & 0.27 \\
\hline 2 & 0.63 & 0.44 & 0.98 & 0.62 & 0.67 & 0.88 & 0.17 \\
\hline 3 & 0.17 & 0.00 & 0.49 & 0.38 & 0.63 & 0.80 & 0.80 \\
\hline 4 & 0.74 & 0.27 & 0.14 & 0.15 & 0.95 & 0.49 & 0.48 \\
\hline 5 & 0.70 & 0.44 & 0.00 & 0.64 & 0.70 & 0.16 & 0.27 \\
\hline 6 & 0.63 & 0.10 & 0.71 & 0.98 & 0.12 & 0.43 & 0.97 \\
\hline 7 & 0.15 & 0.09 & 0.55 & 0.42 & 0.31 & 0.42 & 0.37 \\
\hline 8 & 0.83 & 0.21 & 0.95 & 0.31 & 0.18 & 0.35 & 0.75 \\
\hline 9 & 0.45 & 0.46 & 0.99 & 0.05 & 0.74 & 0.55 & 0.80 \\
\hline 10 & 0.01 & 0.83 & 0.85 & 0.89 & 0.80 & 0.72 & 0.64 \\
\hline 11 & 0.76 & 0.53 & 0.56 & 0.98 & 1.00 & 0.91 & 0.78 \\
\hline 12 & 0.86 & 0.80 & 0.98 & 0.70 & 0.83 & 0.96 & 0.80 \\
\hline 13 & 0.67 & 0.02 & 0.28 & 0.09 & 0.44 & 0.35 & 0.08 \\
\hline 14 & 0.15 & 0.10 & 0.40 & 0.05 & 0.10 & 0.15 & 0.40 \\
\hline 15 & 0.10 & 0.05 & 0.35 & 0.02 & 0.02 & 0.20 & 0.50 \\
\hline 16 & 0.01 & 0.76 & 0.29 & 0.41 & 0.75 & 0.12 & 0.80 \\
\hline 17 & 0.67 & 0.51 & 0.22 & 0.27 & 0.97 & 0.33 & 0.79 \\
\hline 18 & 0.27 & 0.23 & 0.02 & 0.63 & 0.01 & 0.63 & 0.07 \\
\hline 19 & 0 & 0 & 0 & 0 & 0 & 0 & 0 \\
\hline 20 & 1 & 1 & 1 & 1 & 1 & 1 & 1 \\
\hline
\end{tabular}

of different scenarios to select the most feasible CM combination. The importance weights from the ANP decision model are multiplied with the maximum probabilities (1 out of 1 ) to obtain the worst-case scenario of the project. Importance weights and probabilities are summed up to the overall material, equipment, and stabilizing additive scores. Using Eqns (7)-(10), the model is analysed and the resulting CM (M5, E4, S1) output, as shown in Table 12. The result stands for the selection of HIP mix (composed of Marshall and milled asphalt mixes) for the resurfacing activity, biodiesel equipment for the milling activity, and FC-5 layer for the friction course activity.

HIP mix is the best performing material under extreme conditions. The original project utilized Superpave as the asphalt type. However, HIP technology has been evaluated as effective in saving about $50 \%$ cost over the conventional milling and resurfacing, and eliminating $90 \%$ of the emissions resulting from the pavement milling and resurfacing process. Additionally, HIP showed a reduced downtime for pavements being restored in recent projects (EPA 2011). The results under the influence of changing project conditions were also matched with feedback from interviewees, as they approved of the advantages of HIP technology.

The expected result of the proposed model was twofold. First, the selected CM was not only practical and reliable, but also resulted in better resource utilization plans

Table 12. Resource results coded in numbers

\begin{tabular}{llll}
\hline Resource 1 (Mi) Runs: & 5 & HIP Mix \\
\hline Resource 2 (Ei) & Runs: & 4 & Biodiesel equipment \\
\hline Resource $3(\mathrm{Si})$ & Runs: & 1 & FC-5 layer \\
\hline
\end{tabular}


for achieving environmentally conscious construction. Second, the behaviour of the model under the effect of changing probabilities was revealed.

When the probabilities of project conditions were changed, the system selected the most feasible resources based on the probability values. As the inputs for changing project conditions defined the most feasible construction method, the same construction methods were selected under similar scenarios. The influence of changing project conditions was reflected through various scenarios, and the selected CM was the one that outperformed all other methods, including the original one.

Different resources or construction methods were selected by the model for each set of probabilities. Selecting different construction methods resulted in various time, cost, and environmental impact values depending on the probabilities input to the system.

\section{Conclusions}

Construction method selection is a challenging job due mainly to project constraints in the complex construction environment. When the aim is to achieve environmentally conscious construction, the contractor's ability to sustain project performance is based on the selection of resources (e.g. materials and equipment) among all available alternatives under different project conditions. Considering various resource options together with the project conditions, a decision-making mechanism is needed to handle their interrelated effect on the decisions of contractors.

Within this study, components of construction method selection are defined and a decision model is created using ANP. Data from highway construction projects and experts are used to illustrate the dependence of project conditions and resource performance indicators in the decision model. Expert judgment obtained from interviews was aggregated by using the staticizedgroups method. The results of ANP suggested that parameters related to resource performance indicators, which were the properties of various resource options, were ranked as the most important determinants of CM selection. Among the resource performance indicator cluster, stabilizing additive selection had the highest rank, due likely to its role in determining the durability of highway pavement. On the other hand, when project conditions were considered, the two factors (C5: Delay in resource delivery and C4: Unavailability of resources) that were directly related to the availability of resources on site and in a timely manner were ranked as more important than the other parameters. The results implied that the contractors gave high priority to finishing projects within deadline. One of the challenges experienced in this study is collecting data for the pair-wise comparison in the creation of the ANP model. During the interview process, the interviewees need to understand the pair-wise comparison procedure and the nine-point priority scale for ANP. The major difficulty is to convince professionals to dedicate a certain amount of effort and time to this process. Although the comparisons are accurate and consistent for this study, it is a good idea to use brainstorming sessions when the number of interviews is increased.

The initial findings of the study were used to explore the relative importance of a group of project conditions and resource performance indicators on the selection of construction methods. The relative importance results were further used with probabilities to form the CM selection score table. The score table was composed of ranges for resource performance indicators, which enabled the selection of alternatives by using relative importance and probability values. The CM selected was tested and found to be reliable in achieving environmentally conscious construction based on the interviews and previous studies. Although the ANP decision model in this paper was successful in establishing a connection between decision parameters of CM selection, the data was limited to the opinions and experiences of highway professionals. For other types of construction projects, the model needs to be extended.

The proposed ANP decision model supported the selection of the most feasible construction methods based on a group of project conditions and resource performance indicators. The findings of the study emphasized the most important decision parameters and formed a decision-making system that contributes to the progress of environmentally conscious construction studies. The model considered not only decision-making parameters, but also conflicting project objectives to deliver sustainable construction projects with the most feasible construction methods. The decision model can be further improved by sustaining its connection to a simulation model to perform the CM selection on an iterative basis.

\section{References}

Al-Momani, A. H. 2000.Construction delay: a quantitative analysis, International Journal of Project Management 18(1): 51-59. http://dx.doi.org/10.1016/S0263-7863(98)00060-X

Arain, F. M.; Pheng, L. S. 2005. The potential effects of variation orders on institutional building projects, Facilities 23(11): 496-510. http://dx.doi.org/10.1108/02632770510618462

Arun, C.; Rao, B. N. 2007. Knowledge based decision support tool for duration and cost overrun analysis of highway construction projects, Journal of the Institution of Engineers 88(8): 27-33.

Assaf, S. A.; Al-Hejji, S. 2006. Causes of delay in large construction projects, International Journal of Project Management 24(4): 349-357. http://dx.doi.org/10.1016/j.ijproman.2005.11.010

Bahia, H. U. 1993. Bibliographies for physical properties of asphalt cement. SHRP-A-626. National Research Council, Washington, DC, 1-170.

Bishop, I. D.; Stock, C.; Williams, K. J. 2008. Using virtual environments and agent models in multi-criteria decision-making, Land Use Policy 26(1): 87-94. http://dx.doi.org/10.1016/j.landusepol.2008.01.010

Boje, D. M.; Murnighan, J. K. 1982. Group cofidence pressures in iterative decisions, Management Science 28(10): 1187-1196. http://dx.doi.org/10.1287/mnsc.28.10.1187 
Chan, D. W. M.; Kumaraswamy, M. M. 1996. An evaluation of construction time performance in the building industry, Building and Environment 31(6): 569-578. http://dx.doi.org/10.1016/0360-1323(96)00031-5

Cheng, S.; Chan, C. W.; Huang, G. H. 2002. Using multiple criteria decision analysis for supporting decisions of solid waste management, Journal of Environmental Science \& Health A37(6): 975-990. http://dx.doi.org/10.1081/ESE-120004517

Cheng, E. W. L.; Li, H. 2005. Analytic network process applied to project selection, Journal of Construction Engineering and Management 131(4): 459-466.

http://dx.doi.org/10.1061/(ASCE)0733-9364(2005)131:4(459)

Chen, Z.; Heng, L.; Wong, C. T. C. 2005. Environal Planning: analytic network process model for environmentally conscious construction planning, Journal of Construction Engineering and Management 131(1): 92-101.

http://dx.doi.org/10.1061/(ASCE)0733-9364(2005)131:1(92)

Cole, R. J. 1998. Emerging trends in building environmental assessment, Building Research and Information 26(1): 3-16. http://dx.doi.org/10.1080/096132198370065

Dayananda, D.; Irons, R.; Harrison, S.; Herbohn, J.; Rowland, P. 2002. Capital budgeting: financial appraisal of investment projects. $1^{\text {st }}$ ed. Cambridge: Cambridge University Press. $150 \mathrm{p}$.

Dikmen, I.; Birgonul, T. M.; Ozorhon, B.; Sapci, N. E. 2010. Using analytic network process to assess business failure risks of construction firms, Engineering, Construction and Architectural Management 17(4): 369-386. http://dx.doi.org/10.1108/09699981011056574

El-Rayes, K.; Moselhi, O. 2001. Impact of rainfall on the productivity of highway construction, Journal of Construction Engineering and Management 127(2): 125-131.

http://dx.doi.org/10.1061/(ASCE)0733-9364(2001)127:2(125)

EPA. 2009. Potential for reducing greenhouse gas emissions in the construction sector. U.S. Environmental Protection Agency, Washington, DC.

EPA. 2011. Evaluation of the $100 \%$ recyclability of superpave hot mix asphalt [online], [cited 28 October 2012]. Available from Internet: http://cfpub.epa.gov/ncer_abstracts/index. $\mathrm{cfm} /$ fuseaction/display.abstractDetail/abstract/9497/report/0.

Erffmeyer, R. C.; Lane, I. M. 1984. Quality and acceptance of an evaluative task: the effects of four group decisionmaking formats, Group and Organization Studies 9(4): 509-529. http://dx.doi.org/10.1177/105960118400900408

Fischer, G. W. 1981. When oracles fail -acomparison of four procedures for aggregating subjective probability forecasts, Organizational Behavior and Human Performance 28(1): 96-110. http://dx.doi.org/10.1016/0030-5073(81)90017-9

Flórez, L. C. D.; Irizarry, J. 2010. Impact of sustainability perceptions on the purchasability of materials in construction projects, in ASCE Conf. Proc. of Construction Research Congress 2010: Innovation for Reshaping Construction Practice, 8-10 May 2010, Banff, Alberta, Canada.

Frimpong, Y.; Oluwoye, J.; Crawford, L. 2003. Causes of delay and cost overruns in construction of groundwater projects in a developing countries; Ghana as a case study, International Journal of Project Management 21(5): 321-326. http://dx.doi.org/10.1016/S0263-7863(02)00055-8

Fujii, H.; Tanimoto, J. 2004. Integration of building simulation and agent simulation for exploration to environmentally symbiotic architecture, Building and Environment 39(8): 885-893. http://dx.doi.org/10.1016/j.buildenv.2004.01.013

Gangolells, M.; Casals, M.; Gasso, S.; Forcada, N.; Roca, X.; Fuertes, A. 2009. A methodology for predicting the severity of environmental impacts related to the construction process of residential buildings, Building and Environment 44(3): 558-571. http://dx.doi.org/10.1016/j.buildenv.2008.05.001
Hallowell, M. R.; Gambatese, J. A. 2010. Qualitative research: application of the Delphi method to CEM research, Journal of Construction Engineering and Management 136(1): 99-107. http://dx.doi.org/10.1061/(ASCE)CO.1943-7862.0000137

Hanna, A. S.; Russell, J. S.; Vandenberg, P. J. 1999. The impact of change orders on mechanical construction labour efficiency, Construction Management and Economics 17(6): 721-730. http://dx.doi.org/10.1080/014461999371060

Hendrickson, C.; Horvath, A. 2000. Resource use and environmental emissions of U.S. construction sectors, Journal of Construction Engineering and Management 126(1): $38-44$.

http://dx.doi.org/10.1061/(ASCE)0733-9364(2000)126:1(38)

Kua, H. W.; Lee, S. E. 2002. Demonstration intelligent building-a methodology for the promotion of total sustainability in the built environment, Building and Environment 37(3): 231240. http://dx.doi.org/10.1016/S0360-1323(01)00002-6

Larsen, D. A. 2003. Demonstration and evaluation of SUPERPAVE technologies. Final Evaluation Report for CT Route 2, Report No: 2219-F-02-7. Bureau of Engineering and Highway Operations Research and Materials, Connecticut Department of Transportation, Rocky Hill, CT, 1-5.

Lippiatt, B. C. 1999. Selecting cost-effective green building products: BEES approach, Journal of Construction Engineering and Management 125(6):448-455.

http://dx.doi.org/10.1061/(ASCE)0733-9364(1999)125:6(448)

Mukherjee, A.; Rojas, E. M. 2003. Reasoning about actions and events in situational simulations, in Chick, S.; Sdnchez, P. J.; Ferrin, D.; Morrice, D. J. (Eds.). Proceedings of the 2003 Winter Simulation Conference, 7-10 December 2003, New Orleans, LA.

Mukherjee, A.; Rojas, E. M.; Winn, W. D. 2004. Implementing a general purpose framework using multi-agents for construction management education, in Ingalls, R. G.; Rossetti, M. D.; Smith, J. S.; Peters, B. A. (Eds.). Proceedings of the 2004 Winter Simulation Conference, 5-8 December, 2004, Washington, DC.

Mukherjee, A.; Winn, W.; Rojas, E. 2005. Interactive situational simulations in construction management, in The First Conference on the Future of the AEC Industry, 16-17 March 2005, The Building Futures Council, Las Vegas, NV.

Ozcan-Deniz, G.; Zhu, Y. 2011. A systems approach to support the selection of highway construction operations with environmental concerns, in The Proceedings of the International Conference of Construction and Real Estate Management (ICCREM), 18-19 November 2011, Guangzhou University, Guangzhou, Guangdong, China.

Ozorhon, B.; Dikmen, I.; Birgonul, M. T. 2007. Using analytic network process to predict the performance of international construction joint ventures, Journal of Management in Engineering 23(3): 156-163.

http://dx.doi.org/10.1061/(ASCE)0742-597X(2007)23:3(156)

Partovi, F. Y. 2006. An analytic model for locating facilities strategically, Omega 34(1): 41-55. http://dx.doi.org/10.1016/j.omega.2004.07.018

Pulselli, R. M.; Simoncini, M.; Marchettini, N. 2009. Energy and emergy based cost-benefit evaluation of building envelopes relative to geographical location and climate, Building and Environment 44(5): 920-928. http://dx.doi.org/10.1016/j.buildenv.2008.06.009

Rakas, J.; Teodorovic, D.; Kim, T. 2004. Multi-objective modeling for determining location of undesirable facilities, Transportation Research Part D: Transport and Environment 9(2): 125-138.

http://dx.doi.org/10.1016/j.trd.2003.09.002

Roberts, F.; Mohammad, M.; Wang, L. 2002. History of hot mix asphalt mixture design in the USA, Journal of Materials Civil Engineering 14(4): 279-293.

http://dx.doi.org/10.1061/(ASCE)0899-1561(2002)14:4(279) 
Rohrbaugh, J. 1979. Improving the quality of group judgment: social judgment analysis and the Delphi technique, Organizational Behavior and Human Performance 24(1): 73-92. http://dx.doi.org/10.1016/0030-5073(79)90017-5

Rojas, E. M.; Mukherjee, A. 2003. Modeling the construction management process to support situational simulations, Journal of Computing in Civil Engineering 17(4): 273-280.

http://dx.doi.org/10.1061/(ASCE)0887-3801(2003)17:4(273)

Rojas, E. M.; Mukherjee, A. 2006. Multi-agent framework for general-purpose situational simulations in the construction management domain, Journal of Computing in Civil Engineering 20(3): 165-176.

http://dx.doi.org/10.1061/(ASCE)0887-3801(2006)20:3(165)

Russell, M.; Uhlmeyer, J. S.; De Vol, J.; Johnson, C. 2010. Evaluation of hot in-place recycle. Materials Laboratory, MS-47365. Washington State Department of Transportation, Olympia, WA.

Saaty, T. L. 1980. The analytic hierarchy process. New York: Mc Graw-Hill. 287 p.

Saaty, T. L. 1994. How to make a decision: the analytic hierarchy process, Interfaces 24(6): 19-43.

Saaty, T. L. 2001. Decision making with dependence and feedback: the analytic network process. Pittsburgh: RWS Publ., 1-370.

Saaty, T. L. 2001. Decision-making with the AHP: why is the principal eigenvector necessary, in ISAHP Proceedings, 2-4 August 2001, Bern, Switzerland.

Saaty, R. W. 2003. Decision making in complex environments. Pittsburgh: Creative Decisions Foundation.

Saaty, T. L. 2004. Fundamentals of the analytical network process-dependence and feedback in decision-making with a single network, Journal of Systems Science and Systems Engineering 13(2): 129-157.

http://dx.doi.org/10.1007/s11518-006-0158-y

Saaty, T. L. 2005. Theory and applications of the analytic network process: decision making with benefits. opportunities, costs, and risks. Pittsburgh: RWS Publications. 352 p.

Saaty, T. L. 2008. Decision making with the analytic hierarchy process, International Journal of Services Sciences 1(1): 83-98. http://dx.doi.org/10.1504/IJSSCI.2008.017590

Saaty, T. L.; Vargas, L. G. 2006. Decision making with the analytical network process: economic, polytical, socail and technological applications with benefits, opportunities, costs and risks. New York: Springer Science+Business Media, LLC.

Sefair, J. A.; Castro-Lacouture, D.; Medaglia, A. L. 2009. Material selection in building construction using optimal scoring method (OSM), in Construction Research Congress, 5-7 April 2009, ASCE, Seattle, WA.

Selih, J. 2007. Environmental management systems and construction SMES: a case study for Slovenia, Journal of Civil Engineering and Management 13(3): 217-226. http://dx.doi.org/10.1080/13923730.2007.9636440
Shapira, A.; Goldenberg, M. 2007. "Soft" considerations in equipment selection for building construction projects, Journal of Construction Engineering and Management 133(10): 749-760.

http://dx.doi.org/10.1061/(ASCE)0733-364(2007)133:10(749)

Sniezek, J. A. 1990. A comparison of techniques for judgmental forecasting by groups with common information, Group and Organization Studies 15(1): 5-19. http://dx.doi.org/10.1177/105960119001500102

Sun, M.; Meng, X. 2009. Taxonomy for change causes and effects in construction projects, International Journal of Project Management 27(6): 560-572. http://dx.doi.org/10.1016/j.ijproman.2008.10.005

Tuzkaya, G.; Onut, S.; Tuzkaya, U. R.; Gulsun, G. 2008. An analytic network process approach for locating undesirable facilities: an example from Istanbul, Turkey, Journal of Environmental Management 88(4): 970-983. http://dx.doi.org/10.1016/j.jenvman.2007.05.004

UNEP-SBCI 2009. Buildings and climate change: summary for decision makers. United Nations Environment Programme, Paris, France, 3-4.

USGBC 2008. A national green building research agenda [online], [cited 28 October 2012]. Available form Internet: http://www.usgbc.org/ShowFile.aspx?DocumentID=3402

Wang, E.; Shen, Z.; Neal, J.; Shi, J.; Berryman, C.; Schwer, A. 2012. An AHP-weighted aggregated data quality indicator (AWADQI) approach for estimating embodied energy of building materials, International Journal of Life Cycle Assessment 17(6): 764-773. http://dx.doi.org/10.1007/s11367-012-0417-8

Williams, T. M. 2000. Safety regulation changes during projects: the use of system dynamics to quantify the effects of change, International Journal of Project Management 18(1): 23-31. http://dx.doi.org/10.1016/S0263-7863(98)00063-5

Wu, C.; Hsieh, T.; Lu, S.; Cheng, W. 2004. Grey relation analysis of causes for change orders in highway construction, Construction Management and Economics 22(5): 509520. http://dx.doi.org/10.1080/0144619042000202735

Wu, W.; Simpson, A. R.; Maier, H. R. 2010. Accounting for greenhouse gas emissions in multiobjective genetic algorithm optimization of water distribution systems, Journal of Water Resource Planning and Management 136(2): 146-155.

http://dx.doi.org/10.1061/(ASCE)WR.1943-5452.0000020

Zayed, T. M.; Halpin, D. W. 2000. Simulation as a tool for resource management, in Proceedings of the Winter Simulation Conference, 10-13 December 2000, Orlando, FL.

Zeeger, C. V.; Rizenbergs, R. L. 1979. Priority programming for highway reconstruction. Transportation Research Record 698. Transportation Research Board, Washington, DC.

Gulbin OZCAN-DENIZ. He is an Assistant Professor in the Civil and Architectural Engineering and Construction Management department in Milwaukee School of Engineering. She has been teaching construction management topics such as Building Information Modelling (BIM), sustainable construction, project scheduling and estimating. She has published several technical articles in the areas including risk management, simulation and decision-making in construction, life cycle assessment, and sustainable construction methods. Her research interests include sustainable design and development, life cycle assessment and cost, simulation of construction operations, and decision-making techniques.

Yimin ZHU. He is a Professor at the Department of Construction Management at Louisiana State University. His research was funded by various agencies including the General Services Administration (GSA), Electric International (EI), the Florida Department of Transportation (FDOT), the Department of Energy (DOE), and the National Science Foundation (NSF). He has published more than 80 technical articles and reports on topics including computing and applications in construction, building energy simulation, life cycle cost and life cycle assessment. His areas of expertise are Life Cycle Costing (LCC), Life Cycle Assessment (LCA), and building energy modelling. 